\title{
Learning beyond expectations: Evaluation of an international nursing student exchange
}

\author{
Helder Rocha Pereira*1, Maryellen D. Brisbois ${ }^{2}$, Helena Oliveira Silva ${ }^{1}$, Caitlin M. Stover ${ }^{2}$ \\ ${ }^{1}$ School of Health, University of the Azores, Portugal \\ ${ }^{2}$ College of Nursing, University of Massachusetts Dartmouth, United States
}

Received: September 9, 2017

Accepted: October 8, 2017

Online Published: October 19, 2017

DOI: $10.5430 /$ jnep.v8n2p72

URL: https://doi.org/10.5430/jnep.v8n2p72

\begin{abstract}
Background/Purpose: Study abroad programs, through international exchanges in undergraduate nursing schools, are becoming common in response to a globalized world and imperative for nurses to acquire cultural awareness and related competencies. Increased recognition of exchanges exists, with limited empirical evaluation of learning outcomes. The purpose of this study was to understand the impact of a short-term international exchange on Portuguese and American nursing students in respect to its influence on learning.

Methods: A mixed-method research design was utilized for data collection. Online survey (demographic data and revised HPSISN tool) and focus group data collection using synchronous chat groups captured nursing student experiences and perceptions about their participation in a two-sided exchange.

Results: Focus group data from sixteen nursing students (aged 20-39) delineated two major themes: 1) Expectations of the student exchange with three subthemes: a) motivations to participate, b) met versus unmet expectations, and c) beyond expectations; and, 2) Learning (how and what) with six subthemes: a) understanding cultural differences, b) recognizing a different health care system, c) reconsidering the role of the nurse, d) building team work, e) integrating theory into practice, and f) peer mutual learning. Survey data across the four dimensions: 1) Perspectives of exchange, 2) attitude toward community involvement, 3) future professional work and, 4) personal reflection exhibited students acquired personal and professional competencies that were beyond their expectations of the exchange.

Conclusions: Results strongly support nursing student participation in international exchange programs develops personal growth and professional competencies that may impact future practice when caring for diverse patient populations. Universities should develop and foster global programs for student engagement.
\end{abstract}

Key Words: Undergraduate nursing education, Student exchange, Program evaluation, Global competencies, Personal and professional growth, Research with vulnerable populations

\section{INTRODUCTION}

Study abroad programs in undergraduate nursing colleges and universities are becoming more common in response to an increasingly globalized world, while the need for fostering cultural competence and cultural awareness in nursing education has been recognized. ${ }^{[1,2]}$ These competencies are crucial when caring for diverse patient populations in a variety of settings. ${ }^{[3,4]}$

Nurses often feel a lack of preparation in caring for patients from diverse populations. ${ }^{[5]}$ This may lead to poor health outcomes and health disparities ${ }^{[5]}$ among the patients under their care; with those receiving culturally sensitive care realizing

*Correspondence: Helder Rocha Pereira; Email: helder.ja.pereira@uac.pt; Address: School of Health, University of the Azores, Portugal. 
a potential reduction in disparities. ${ }^{[6]}$ As a result, health care institutions are pursuing nurses who possess the knowledge and skills to provide culturally and linguistically competent care to diverse patient populations, ${ }^{[4]}$ and "cultivate leaders to enrich the nursing profession, locally and globally". ${ }^{[3]}$

Over the past ten years, international exchange programs have been established to raise cultural and global awareness in nursing students, ${ }^{[7,8]}$ with the goal of developing culturally competent practitioners. ${ }^{[9,10]}$ These programs have become a significant pedagogy in nursing to increase students understanding of cultural competence and intercultural sensitivity. ${ }^{[10]}$

Common benefits of international nursing exchange programs are reported as (a) learning cultural differences, ${ }^{[3,4,11]}$ building cultural competence, ${ }^{[5,9,10]}$ comparing health care systems and nursing practice, ${ }^{[12,13]}$ personal growth, ${ }^{[13,14]}$ career development, ${ }^{[3,10,15]}$ cognitive development, ${ }^{[9,10]}$ transcultural adaptation, ${ }^{[3]}$ understanding of population-based health care problems, ${ }^{[14]}$ improvement in linguistic capabilities, ${ }^{[4,13]}$ team work, ${ }^{[8]}$ and developing an awareness of one's own culture, structure and practice that impact the student and the world, ${ }^{[9,15]}$ and aid students in becoming better global citizens. ${ }^{[16]}$

Nursing education has shifted to institutions of higher education across the globe, permitting student and faculty exchanges to become more readily obtainable. ${ }^{[12]}$ Nursing students frequently have multiple commitments with family and work responsibilities, ${ }^{[3]}$ and rigid curriculum requirements that prohibit extended periods away. Consequently, short-term exchange programs have become more commonplace. While increased recognition regarding the significance of a student exchange exists, ${ }^{[10]}$ empirical data on the assessment of learning outcomes for the student experience remain limited. ${ }^{[1]}$ This lack of data creates a gap in overall understanding of the benefits obtained by undergraduate nursing students who study abroad and requires further investigation.

Therefore, the purpose of this study was to understand the impact of a short-term international exchange on Portuguese and American nursing students in respect to its influence on learning.

\section{About the student exchange}

A two-week short-term nursing student exchange program between a university in Portugal and a university in the United States (U.S.) was designed. The mission of this exchange was to create a sustainable international alliance in community health among Portuguese and American nursing faculty and students. This two-sided inaugural exchange took place during the spring as part of a semester long Community Published by Sciedu Press
Health experiential course with parallel objectives and outcomes in both curriculums. Each group consisting of two faculty and eight students from each university prepared for the exchange 7 weeks pre-departure, followed by one week in the opposite country, and meetings with debriefing and discussion continuing post immersion.

Prior to the exchange, students attended language classes (Portuguese or English), reviewed and critiqued literature and related sources (laws, codes of ethics, human rights declarations, film, and meetings with community agencies who support deportees) regarding the history of immigration and deportation from Portugal to the U.S.; as men and women who had been deported back to Portugal from the U.S. were identified through key informants in both countries as a vulnerable group with potential unmet health needs. Additionally, students met their international peers via videoconference and were 'paired' with a student from the opposite country to work on a research initiative with deportees. In Portugal, students collected health related data with deportees with community agency and faculty support. In the U.S., faculty and students met with family members of deportees in a community agency to understand the perspective of the families of those deported. Students shared their experiences through meetings with key informants, agencies, health professionals and academic venues in both countries. To support learning, students were engaged in cultural experiences, toured health care facilities, attended classes, and deliberated nursing education models.

\section{MeTHODS}

\subsection{Design}

A mixed-method (MM) research design, using both quantitative and qualitative questions, was utilized for data collection, in survey and focus group format. The advantage of using a MM approach is to triangulate quantitative and qualitative data to help avoid limitations and rigidity of a single approach, address exploratory questions, enhance validity of results, and allow for collaboration of quantitative and qualitative researchers. ${ }^{[17]}$

\subsection{Procedures and data collection}

A revised version of Shinnamon, Gelmon, \& Holland's $(1999)^{[18]}$ Health Professions Schools in Service to the Nation (HPSISN) survey was administered online with quantitative questions via Survey Monkey link format. The demographic data information sheet and revised tool were translated from English to Portuguese so students could choose which version they were most comfortable completing.

Qualitative data were collected via online synchronous focus groups (OSFG) using Crusader Services (c) 2015 software 
to capture student experiences from both Portugal and the U.S. OSFG mimic group interaction of face-to-face (F2F) focus groups; with no significant differences in themes that emerged from F2F focus groups when compared to focus groups replicated online. ${ }^{[19]}$ OSFG were noted to be an effective strategy to access participants in this study, and maintain their anonymity to address a potential power relationship between faculty and students, or hesitation of participants to answer questions truthfully for fear of hurting faculty feelings. The use of OSFG in this study was replicated from a protocol previously set forth with university students. ${ }^{[20]}$ As each participant joined the synchronous chat room, a randomly assigned number replaced their name (P1, P2, etc.).

Data were collected at two different time points (Portuguese and American students participated in separate groups), approximately 3.5 months following the student exchange, to accommodate different time zones and schedules. Faculty from each university and a group moderator were present during both OSFG, along with an interpreter to allow for immediate translation of student responses. This translation allowed for dynamic follow-up questions and ongoing conversations that might not have occurred in $\mathrm{F} 2 \mathrm{~F}$ groups due to language barrier.

\subsection{Measures}

The HPSISN tool was originally developed to evaluate service-learning in the health professions. ${ }^{[18]}$ The researchers felt the tool was valuable, but would be clearer for students to respond if the language reflected a student exchange experience. Three of the four researchers reviewed each question carefully, separately, and together, and came to the same conclusions regarding change of language across items and face validity of the individual questions. Permission to modify and translate the revised survey to Portuguese was approved. The intent of the modified survey was to assess students engaged in an inaugural student nursing exchange between Portuguese and American university students working with a vulnerable group in the community.

The original HPSISN (1999) tool included 33 quantitative questions, a qualitative open-ended comment question, and 8 focus group questions to measure four dimensions: perspectives of exchange, attitudes toward community involvement, influence of exchange on future professional work, and personal reflections and capture the impact of service learning on students. The goal of a revised version would be to similarly understand the impact of a student exchange on students, its influence on learning, view of service, choice of career/specialization, and perspectives on working in a diverse community. Whenever possible, directions for administering the tool, demographic data questions, and content topics were preserved in the modified survey. The format and flow of the original survey (quantitative and qualitative) was also maintained.

The HPSISN (1999) tool has been described in dissertation studies, among graduate students, and in studies with physical therapy students, ${ }^{[21]}$ nursing, and medical students. ${ }^{[22]}$ These two studies were related to service learning with findings broadly describing benefits to both students and the communities where they were immersed.

The newly revised HPSISN Student Exchange Survey included 29 quantitative questions, one open-ended response, and 8 focus group questions. Of the 29 quantitative questions, 7 demographic data questions were asked. The remaining 22 quantitative questions related to student perspectives of the exchange (7 questions), attitudes toward community involvement (6 questions), influence of exchange on future professional work (3 questions) and personal reflection about their experience (6 questions). These 22 questions were based on a 5-point Likert scale with student responses ranging from Strongly Disagree (SD) to Strongly Agree (SA). For purposes of data analysis negatively worded questions (4 and 11) were reworded and reordered from SA to SD. Psychometric data of the original HPSISN (1999) tool was not accessible in the literature at the time this manuscript was written. Cronbach's alpha coefficient for the revised HPSISN Student Exchange Survey in this study was 0.914 to provide readers a baseline for tool reliability in future studies.

\subsection{Ethical considerations}

Exceptional care was taken to ensure that student participation in this study was voluntary. The moderator of the focus groups was an investigator without previous contact with the students or the exchange program. Participant anonymity was maintained. In place of a signed informed consent form, a cover letter/fact sheet was posted on the virtual room white board. Once participants read the fact sheet and voluntarily agreed to participate in this focus group, they were asked to type the word AGREE. If they did not wish to participate in this focus group, they wrote DO NOT AGREE. If they wrote DO NOT AGREE or did not respond, they were excused from the virtual chat room. Institutional Review Board approval for this study was obtained from the university in the U.S.

\subsection{Data analysis}

Quantitative data analysis was performed through descriptive statistics providing a mean and standard deviation, as original tool authors ${ }^{[18]}$ recommended descriptive statistics as being most useful to provide a rich profile of the sample for demographic data and responses to individual items. 
Qualitative interview data from the Portuguese group were translated to English as soon as possible after OFSG was complete. Translated interviews were reviewed by three researchers to ensure completeness and accuracy. OSFG interview transcripts were analysed following the principles of qualitative content analysis. The texts were read repeatedly by the researchers to organize data into meaningful subsections by hand, according to the questions posed into segments, closely examined, and compared to other segments for areas of convergence and divergence to create emergent themes and subthemes.

\section{Results}

\subsection{Sample demographic characteristics}

Eight junior nursing students from each university $(\mathrm{N}=16$; aged 20-39; $\mathrm{M}=23.12 ; \mathrm{SD}=4.349)$ consisted of three males $(19 \%)$ and thirteen females $(81 \%)$ who enrolled in a semester long experiential Community Health course, with a two-week exchange component, participated in this study (see Table 1).

Table 1. Sample demographic data age

\begin{tabular}{ll}
\hline Age & $\mathbf{N}(\mathbf{\%})$ \\
\hline$<20$ & - \\
$20-24$ & $15(94 \%)$ \\
$25-29$ & - \\
$30-34$ & - \\
$35+$ & $1(6 \%)$ \\
M & 23.12 \\
SD & 4.349 \\
\hline
\end{tabular}

Sixty two percent of participants had work commitments in addition to their educational responsibilities; with hours of work ranging from 1-40 hours/week as shown in Table 2. One student completed the demographic and student exchange survey via Survey Monkey, but did not participate in the OSFG.

Table 2. Sample demographic data hours worked

\begin{tabular}{ll}
\hline Current work status/week & N (\%) \\
\hline 1-10 hours & $2(12.5 \%)$ \\
$11-20$ hours & $5(31 \%)$ \\
$21-30$ hours & $1(6 \%)$ \\
$31-40$ hours & $2(12.5 \%)$ \\
41+ hours & - \\
I do not currently have a job & $6(38 \%)$ \\
\hline
\end{tabular}

\subsection{Quantitative data}

Participants responded positively to the perspectives of exchange dimension. Overwhelmingly, students "Agreed" or
"Strongly Agreed" on items related to community participation, understanding material from lectures and reading, need to implement more exchange experiences into classes at their university, the exchange experience directly linked to building clinical skills, made students take more responsibility for their own learning, aware of roles of health professionals in disciplines other than nursing, and the desire to enroll in additional student exchange opportunities offered in their nursing programs. The two items with the highest scores (SA) were their willingness to participate again in an exchange opportunity $(\mathrm{M}=4.81, \mathrm{SD}=0.403)$, and take responsibility for their own learning $(\mathrm{M}=4.75, \mathrm{SD}=0.447)$.

Participant responses were dispersed across the scale in four items related to attitudes toward community involvement. Students SA or A that this exchange experience helped them to become more aware of the needs of the community and their responsibility to serve the community. The two items with the lowest scores were their volunteerism before the exchange $(\mathrm{M}=3.31, \mathrm{SD}=1.302)$, and that their work during the exchange benefitted the community $(\mathrm{M}=3.93$; $\mathrm{SD}=$ 0.928).

In response to the influence of exchange on future professional work dimension, participants reported a higher mean regarding the influence of the exchange helping define their personal strengths and weaknesses $(\mathrm{M}=4.50 ; \mathrm{SD}=0.632)$, when compared to questions regarding the exchange helping to clarify career/specialization choice $(\mathrm{M}=3.62 ; \mathrm{SD}=$ $0.806)$, and future career in community nursing $(\mathrm{M}=3.75$; $\mathrm{SD}=0.774$ ). These last two items are amongst the lowest means across all dimensions.

Responses to personal reflections on exchange questions resulted in participants expressing good relationships with their instructor(s) during the exchange experience $(\mathrm{M}=4.62$; $\mathrm{SD}=0.500$ ), and becoming more comfortable working with people different from themselves $(\mathrm{M}=4.62 ; \mathrm{SD}=0.500)$.

Participant responses were similar across the tool in four items related to: Becoming more aware of their own biases and prejudices $(\mathrm{M}=4.31, \mathrm{SD}=0.602)$, enhancing leadership skills $(M=4.37, S D=0.957)$, enhancing their ability to communicate ideas in a real-world context $(\mathrm{M}=4.37, \mathrm{SD}=$ 0.619 ), and ability to make a difference in the community $(\mathrm{M}=4.37, \mathrm{SD}=0.718)($ see Table 3$)$.

The overall mean score of the revised HPSISN with four dimensions combined (22 questions) was $\mathrm{M}=4.28$; $\mathrm{SD}=$ 0.274 . The highest mean score mean score was 4.57 (SD $=0.161$ ) for the perspectives of exchange dimension and the lowest mean score was $3.95(\mathrm{SD}=0.475)$ for the future professional work dimension (see Table 4). 
Table 3. Student-exchange survey* 2015 results $(\mathrm{N}=16)$

\begin{tabular}{|c|c|c|c|c|c|c|c|}
\hline Dimension & $\begin{array}{l}\text { Strongly } \\
\text { Disagree } \\
\text { N (\%) }\end{array}$ & $\begin{array}{l}\text { Disagree } \\
\text { N (\%) }\end{array}$ & $\begin{array}{l}\text { Neutral } \\
\text { N (\%) }\end{array}$ & $\begin{array}{l}\text { Agree } \\
\text { N (\%) }\end{array}$ & $\begin{array}{l}\text { Strongly } \\
\text { Agree } \\
\text { N (\%) }\end{array}$ & $\mathbf{M}$ & SD \\
\hline \multicolumn{8}{|l|}{ I. Perspectives of exchange } \\
\hline $\begin{array}{l}1 \text { The community participation aspect of this } \\
\text { student exchange had a positive impact on me that } \\
\text { can be used in everyday life }\end{array}$ & & & & 7 (44\%) & $9(56 \%)$ & 4.56 & 0.512 \\
\hline $\begin{array}{l}2 \text { Participation in this student exchange helped me } \\
\text { to better understand the material from my lectures } \\
\text { and readings }\end{array}$ & & & $1(6 \%)$ & $4(25 \%)$ & $11(69 \%)$ & 4.62 & 0.619 \\
\hline $\begin{array}{l}3 \text { Student exchange experiences should be } \\
\text { implemented into more classes at my } \\
\text { university/college }\end{array}$ & & & $1(6 \%)$ & $6(38 \%)$ & $9(56 \%)$ & 4.50 & 0.632 \\
\hline $\begin{array}{l}\text { 4 My student exchange experience was directly } \\
\text { linked to building clinical skills** }\end{array}$ & & $1(6 \%)$ & & $7(44 \%)$ & $8(50 \%)$ & 4.37 & 0.806 \\
\hline $\begin{array}{l}5 \text { Participation in this student exchange made me } \\
\text { take more responsibility for my own learning }\end{array}$ & & & & $4(25 \%)$ & $12(75 \%)$ & 4.75 & 0.447 \\
\hline $\begin{array}{l}6 \text { This student exchange made me more aware of } \\
\text { the roles of health professionals in other disciplines } \\
\text { besides my own }\end{array}$ & & & $1(6 \%)$ & $7(44 \%)$ & $8(50 \%)$ & 4.43 & 0.629 \\
\hline $\begin{array}{l}7 \text { I would like to enroll in additional student } \\
\text { exchange opportunities offered through my degree } \\
\text { program }\end{array}$ & & & & $3(19 \%)$ & $13(81 \%)$ & 4.81 & 0.403 \\
\hline \multicolumn{8}{|l|}{ II. Attitudes toward community involvement } \\
\hline $\begin{array}{l}8 \text { I was already volunteering before this student } \\
\text { exchange experience }\end{array}$ & $2(12.5 \%)$ & $3(19 \%)$ & $1(6 \%)$ & $8(50 \%)$ & $2(12.5 \%)$ & 3.31 & 1.302 \\
\hline $\begin{array}{l}9 \text { This student exchange experience showed me } \\
\text { how I can become more involved in my community }\end{array}$ & & & $2(12.5 \%)$ & $5(31.5 \%)$ & $9(56 \%)$ & 4.43 & 0.727 \\
\hline $\begin{array}{l}10 \text { I feel that the work I did through this student } \\
\text { exchange experience benefited the community }\end{array}$ & & $1(6 \%)$ & $4(25 \%)$ & $6(38 \%)$ & $5(31 \%)$ & 3.93 & 0.928 \\
\hline $\begin{array}{l}11 \text { I will probably volunteer or continue } \\
\text { community involvement after this course or } \\
\text { curricular unit of study** }\end{array}$ & & $\begin{array}{l}1 \\
(6.25 \%)\end{array}$ & $1(6.25 \%)$ & $5(31.25 \%)$ & $9(56.25 \%)$ & 4.37 & 0.885 \\
\hline $\begin{array}{l}12 \text { This student exchange experience helped me to } \\
\text { become more aware of the needs in the community }\end{array}$ & & & & $7(44 \%)$ & $9(56 \%)$ & 4.56 & 0.512 \\
\hline 13 I have a responsibility to serve the community & & & & $7(44 \%)$ & $9(56 \%)$ & 4.56 & 0.512 \\
\hline \multicolumn{8}{|l|}{$\begin{array}{l}\text { III. Influence of exchange on future professional } \\
\text { work }\end{array}$} \\
\hline $\begin{array}{l}14 \text { Participating in this student exchange helped me } \\
\text { to define my personal strengths and weaknesses }\end{array}$ & & & $1(6 \%)$ & $6(38 \%)$ & $9(56 \%)$ & 4.50 & 0.632 \\
\hline $\begin{array}{l}15 \text { Participating in this student exchange helped me } \\
\text { clarify my career/specialization choice }\end{array}$ & & & $9(56 \%)$ & $4(25 \%)$ & $3(19 \%)$ & 3.62 & 0.806 \\
\hline $\begin{array}{l}16 \text { I will consider community nursing in my future } \\
\text { career plans because of this student exchange }\end{array}$ & & & $7(43 \%)$ & $6(38 \%)$ & $3(19 \%)$ & 3.75 & 0.774 \\
\hline \multicolumn{8}{|l|}{ IV. Personal reflections on exchange } \\
\hline $\begin{array}{l}\text { 17 I developed a good relationship with my } \\
\text { instructor(s) during the student exchange } \\
\text { experience }\end{array}$ & & & & $6(37.5 \%)$ & $10(62.5 \%)$ & 4.62 & 0.500 \\
\hline $\begin{array}{l}18 \text { During this experience, I became more } \\
\text { comfortable working with people different from } \\
\text { myself }\end{array}$ & & & & $6(37.5 \%)$ & $10(62.5 \%)$ & 4.62 & 0.500 \\
\hline $\begin{array}{l}19 \text { Participating in this student exchange made me } \\
\text { more aware of some of my own biases and } \\
\text { prejudices }\end{array}$ & & & $1(6 \%)$ & $9(56 \%)$ & $6(38 \%)$ & 4.31 & 0.602 \\
\hline $\begin{array}{l}20 \text { Participating in this student exchange helped me } \\
\text { enhance my leadership skills. }\end{array}$ & & $1(6 \%)$ & $2(12.5 \%)$ & $3(19 \%)$ & $10(62.5 \%)$ & 4.37 & 0.957 \\
\hline $\begin{array}{l}21 \text { The work I performed as part of this student } \\
\text { exchange enhanced my ability to communicate my } \\
\text { ideas in a real-world context }\end{array}$ & & & $1(6 \%)$ & $8(50 \%)$ & $7(44 \%)$ & 4.37 & 0.619 \\
\hline 22 I can make a difference in the community & & & $2(12.5 \%)$ & $6(37.5 \%)$ & $8(50 \%)$ & 4.37 & 0.718 \\
\hline
\end{tabular}


Table 4. Mean scores and standard deviation of each dimension and dimensions combined

\begin{tabular}{lll}
\hline Revised HPSISN Dimensions & M & SD \\
\hline Perspectives of exchange (7 questions) & 4.57 & 0.161 \\
Attitude toward community involvement (6 questions) & 4.19 & 0.491 \\
Future professional work (3 questions) & 3.95 & 0.475 \\
Personal reflection (6 questions) & 4.44 & 0.138 \\
All dimensions combined (22 questions) & 4.28 & 0.274 \\
\hline
\end{tabular}

\subsection{Data from online synchronous focus groups}

Two major themes emerged from the OSFG that were entitled Expectations of the student exchange, and Learning (The How and What). Expectations of the student exchange theme was divided into three subthemes: motivations to participate, met versus unmet expectations, and beyond expectations. The second major theme Learning was divided into 6 subthemes related to their experience that included understanding cultural differences, recognizing a different health care system, reconsidering the role of the nurse, building team work, integrating theory into practice, and peer mutual learning. The themes and subthemes are described in the following section and depicted in Figure 1.

\subsubsection{Expectations of the student exchange 1) Motivations to participate}

Despite having little information prior to this inaugural exchange, participants were motivated to enroll in the program for two main reasons: To overcome personal challenges and/or to foster nursing and professional competencies. Participant numbers (P1, P2, etc.) were appropriated following the quotes used to describe their motivation. The catalysts for participants to enroll were as diverse as a/an:

(i) Desire to travel to another country and culture. "Because I like new experiences, adventures (...) to have the opportunity of knowing a new country" (P4);

(ii) Challenge to overcome personal limitations. "I have never really done anything outside of my city because of my fear of being away from my family and relying on others, so this was an opportunity for me to grow and become an individual and take charge, if you will" (P14);

(iii) Special interest in developing competencies useful for the profession; such as teamwork, communication skills with patients of different cultures, and how to deal with the different and unknown. "To have new experiences and work with a working team from a different culture. Besides overcoming a challenge. Overcoming linguistic and cultural barriers which I consider a gain to my professional future" (P2);

(iv) Interest in knowing and analyzing how the corresponding country works in respect to nursing education and health

Published by Sciedu Press care delivery. "Getting to know a new health system and nursing teaching. To know what is the nurse's role on the health team" (P2); and,

(v) desire to be engaged in an unconventional way of learning to which they attributed value and potential selftransformation, "I was very interested in looking at social needs of another country and how they form their healthcare system. I think that can offer amazing perspectives on our own here in the U.S., and make us empowered to make change in the future. I expected to learn culture and new ways to look at social needs, but develop a sense of giving back to the community and helping others outside of the hospital" (P10).

\section{2) Met versus unmet expectations}

Overall, participants retrospectively assessed their initial expectations of the exchange as being "achieved" and "overcome". These expectations included: Meeting course learning outcomes, cultural competence, language acquisition, and improved communication skills.

Participants also described an evolutionary process regarding their self-awareness and personal growth during the student exchange, "They [exchange programs] give you a global perspective of your education and help you to see things from other views" (P14); and, "I also agree that there were a lot of moments for everyone where self-reflection and self-growth was critical, myself included" (P10).

Considering the exchange was organized around a research study to understand of the health of a vulnerable group in the community (men and women who had been deported from the U.S. to Portugal), participants expressed a level of frustration by noting it would have been useful for them to collaborate with tool design prior to data collection to feel more confident during the interview process.

Another unmet expectation that generated discussion among participants was related to the impact of their work with deported persons. "One thing that wasn't met was that I thought we would be more closely working with the deportees and have a chance to help them, but instead we were only able to listen, and possibly help in the future" (P11).

During data collection, participants also questioned whether the interviews they conducted gave false hope to the deportees, or if data collection, without follow up support, was useful. "How are we going to help change some of these problems is my biggest question (...) that is also a fear of mine that we are not going to be able to make a difference" (P14). "Honestly, I don't know if we helped them or not" (P7). 
While some participants raised concern that collected data may not be helpful to the deportees, others described their dissemination of project results to the local community (via university symposium, local newspaper, television, and radio outlets) in both countries was a way to raise awareness about the plight of the deportees globally. "I think we can sensitize people and create awareness about this population", (P7); and, "With this work, we helped our community change their views on this group more than with the deportees themselves" (P5).

In the same light, participants questioned whether the information gathered during this exchange would be utilized to implement future related projects. "Is the next exchange going to work to help with the information we collected?" (P13). Clarification of intended future interventions with deportees would allow participants to overcome feelings of helplessness.

On the other hand, participants expressed that work assigned during the exchange surpassed the workload typical of a single semester, and as a result, students lacked closure. "We were able to meet many of our goals, and all the students in this exchange benefited from this exchange (I believe). The one glaring hole I believe is that I never felt like the exchange ended... there were no conclusions and no final decisions, if that makes sense. I kind of feel like we did a lot of work and still are trying to put the final pieces together" (P11).

\section{3) Beyond expectations}

Participants frequently described their experience during the exchange by using words such as "beyond" and "unexpected". They were pleasantly surprised by the positive impact of unanticipated gains that were beyond the explicit outcomes of the program. They illustrate this idea of unanticipated gains across several diverse situations that included:

(i) being able to adjust quickly to new and challenging situations while working in an unknown and ever-changing environment. "Not knowing exactly what was happening was bit unnerving, but I feel as though it helped us learn that in some aspects of nursing you need to think quick and adjust to a changing situation, this exchange gave us experience with that" (P15);

(ii) acknowledging that being exposed in a meaningful way to a new cultural and diverse community produces, in a person, a transformation about how they assess their own community, or by understanding another reality, participants felt better able to understand their own reality. "I learned so much, now whenever there are issues going on in my city, I always compare them globally, and think what they are going through" (P14); (iii) connecting with other professionals working in a different healthcare setting allowed them to reassess their own health care experiences and practice in clinical and workplace. "We got to see that there is more than one right way to conduct nursing care, which I think many of us had not considered before." (P16). "I always think about the healthcare system there whenever I want to go to the doctor, or the hospital, [or] even to work, I always am comparing it to my experience in Portugal" (P14); and,

(iv) creating a new way of thinking which involved the ability to look at themselves from a different lens. "Not only do you cover the set of learning objectives, students also take home more than that. They also have the opportunity to view another country, and also take-home lessons that may be applicable to their career and life in general" (P12).

Participant descriptions of "surprising" and "unanticipated and lasting" gains beyond those explicit in the program is a major reason they would recommend this experience during an undergraduate nursing program. "I would truly recommend a student exchange as a part of their curriculum, because not only do you cover the set learning objectives, students also take home much more than that. They have the opportunity to view another country and take-home lessons that may be applicable to their career and life in general" (P12); "I like new experiences and new opportunities (...) and I think that is what this project was, a very different experience where we can learn different things from what we are used to, meaning; it made us move a little beyond what we were expecting" (P3).

\subsubsection{Learning: The how and what}

As part of the discourse among participants, learning outcomes they considered most relevant were identified. Some results were expected, due to the design of the exchange; such as those related to exposure to a new culture and health care system. Other outcomes emerged from the dynamics created between participants and their shared experiences during the exchange; seen as valuable lessons regarding their future role as a nurse.

\section{1) Understanding cultural differences}

As part of the exchange, participants were exposed to cultural opportunities (attending classes, museum tours, new architecture, college living, daily routines, religion, natural surroundings, and music) through planned activities in both countries. They described these opportunities as beneficial to them as they. "Allowed me to get to know a different culture, another reality to get over the linguistic barrier. I expanded my academic and human relations knowledge" (P1). 


\section{2) Recognizing different health care systems}

Participants were also engaged in interactive tours (community health centers, acute care hospitals, community agencies working with vulnerable populations) and attended meetings with interdisciplinary teams, and could pose questions, receiving immediate feedback. During these visits, they gained new knowledge regarding the health care delivery system and health insurance structure in the opposing country. "For example, I think they had no idea we don't have health insurance the same way they do" (P8).

\section{3) Reconsidering the role of the nurse}

The profound awareness of the potential of being a nurse in a different setting (especially in the community) emerged frequently in student responses. For some, the realization of the role of a community nurse had not been considered before. "The community nurse, has a connection with the community service which is the key to support [these] groups" (P2); "I would have never imagined that I was going to meet such great people and develop such a love for community nursing as I have now" (P14). For other participants, they realized the importance of nursing interventions among vulnerable groups, and outside of traditional health care settings where they typically see nurses working.

These descriptions allowed them to consider the broader role of a nurse, and their future professional lives. "I love the idea, many programs do not allow for abroad experiences to fit cohesively into their curriculum, and I believe this exchange was an eye-opening experience that many students should experience. I feel as though it will definitely change your outlook on nursing” (P15).

\section{4) Building teamwork}

Learning to work with students in a team from a different culture, language, background, and nursing education model was one of the most valued, albeit challenging learning experiences described during the exchange; with an anticipated impact on their future career. "There's no 'I' in team, and you will always have other views to consider. Working with a group is no easy task but one that is crucial to any kind of nursing” (P10).

Among valued skills related to teamwork, participants developed their ability to manage tension in a group, achieve group consensus, plan activities together, delegate responsibility, and be held accountable. "At times there was tension, 8 different personalities spending as much time together as we did can get hard. We were all mature enough to agree to talk it out though, and we weren't alone; the Portuguese [group] had to do the same exact thing while we were there; stress just gets the best of everyone sometimes" (P15).

Participants focused on more than group dynamics needed to build a team toward a common goal, but described the importance of support within a group when facing challenging, uncertain and stressful situations. "You are never alone; you will always have a group to confer with" (P15).

\section{5) Integrating theory into practice}

The guided experience of being immersed in an unknown culture, in a different geographical setting, provided a catalyst for enhanced learning and reflection among participants. The dimension of understanding the reality of a phenomenon (such as the health and quality of life of deported people) while in direct contact with community agencies was valued as a highly substantial learning experience. "One thing is to study; another is to be in loco" (P1); "We were able to see first- hand some of the things that were in our textbook" (P14); "The interviews with people subjected to deportation made me put in practice and understand the cycle of vulnerability” (P2).

The perspective of immersing in a community; living as people live, working with students and professionals in a real work setting for a continuous period, provided a rich experience for participants enrolled in this study. They considered this as more beneficial than more traditional clinical experiences that meet weekly. "I feel the exchange we had was a greater submersion into the community than what other students receive, simply going once a week for several hours, for one semester" (P15).

\section{6) Peer mutual learning}

To support the learning goals of the exchange program, students were divided into pairs (one Portuguese, one American) to conduct data collection with deportees. This pairing of students led to deepened bonds that allowed them to rely on their partner, not only as a resource for educational activities, but to help navigate a new country. This relationship was highly valued by students as privileged; allowing for mutual learning. "[This was] mutual helping; in here we worked as the bridge, and in the USA, they were our bridge because of the linguistic barrier" (P4); "It was great to learn about the perceptions from another person around my age from a different country; it opened my eyes" (P14); and, "This part was amazing. I knew I had my exit buddy to go to, to check in with. In Portugal, I could approach anyone [in the group]; it allowed for 'one on one time' to really connect" (P10).

\subsubsection{Integrating quantitative and quantitative data}

Overall, quantitative and qualitative results were similar among Portuguese and American participant responses. Two 
questions (10 and 20) from the revised HPSISN elicited more diverse responses related to exchange-related work as benefiting the community, and their participation in this exchange as helping them enhance leadership skills; with Portuguese participant responses to these two questions more likely to be 'Neutral' or 'Disagree'.

The highest SA and A scores across the tool were related to the exchange having a positive impact on the students, an increased awareness of the needs in the community, encouraged more responsibility for their own learning, and increased self-awareness (related to personal strengths and weaknesses, and own biases and prejudices). Quantitative and qualitative results from this mixed method study were combined and depicted in Figure 1 to integrate data.

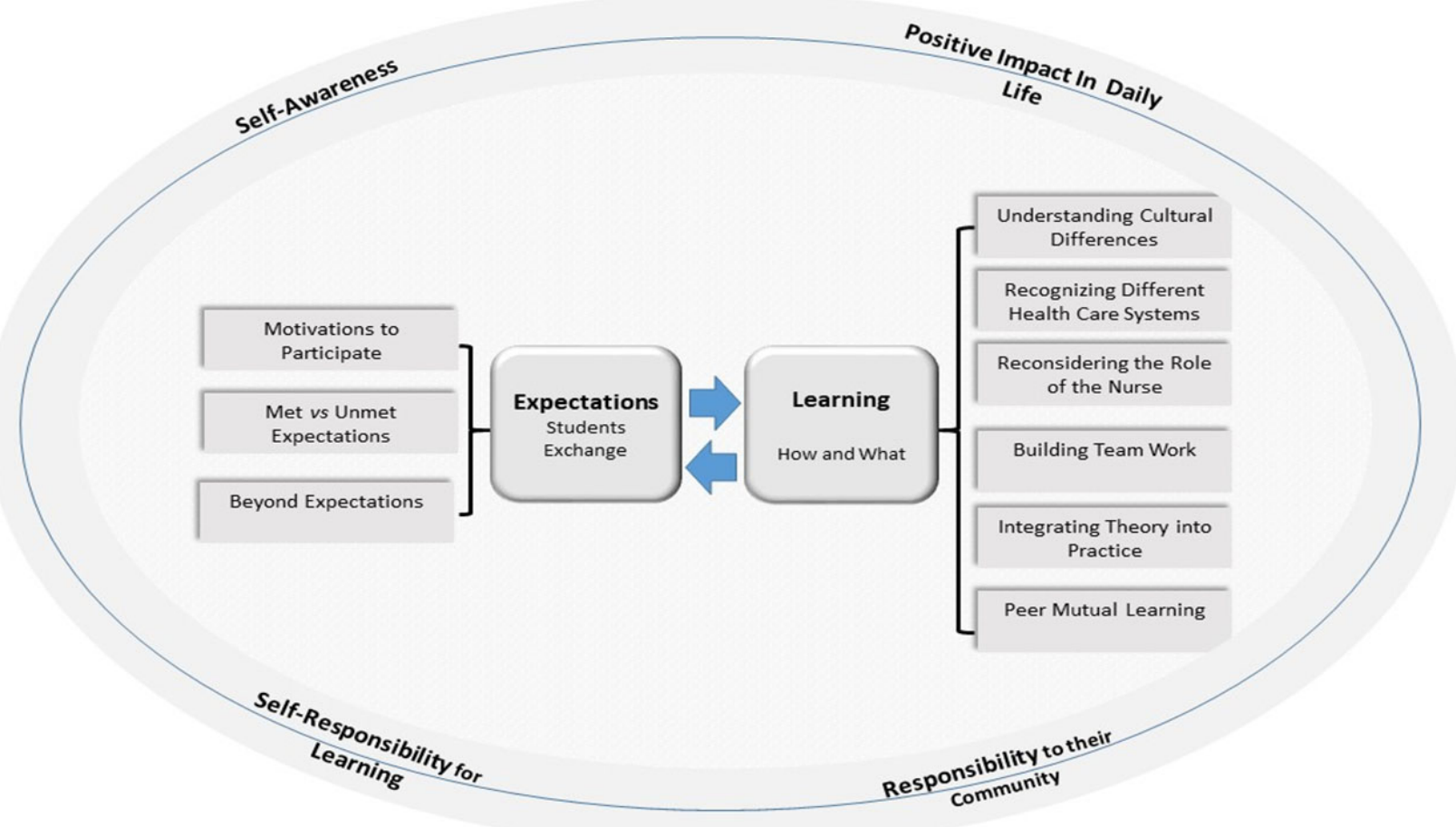

Figure 1. Learning Beyond Expectations: Results from two-sided nursing student exchange

\section{Discussion}

In recent years, there has been a proliferation of international programs implemented by undergraduate nursing programs to respond to the growing need to provide culturally sensitive care to diverse populations across the globe. International programs can emphasize different strategies such as: Providing service-learning experiences in disadvantaged settings, two-sided exchange programs, or participating in a study abroad program for an extended period of time. ${ }^{[2]}$ These different strategies aim to achieve outcomes, as documented in the literature, as increasing student exposure to cultures and systems different from those familiar to them. ${ }^{[1]}$

The evaluation of this two-sided exchange program closely aligns with the gains reported in the literature; which showed an increased capacity for students to reflect on the professional role of the nurse beyond a traditional setting. ${ }^{[10,15]}$ However, while participants understood the expanded role of the nurse in the community during the exchange, this ex- perience did not have an impact on their projected nursing specialization choice.

This type of community exposure can allow students to value learning experiences that, although theoretically addressed, are often undervalued in domestic clinical learning settings. With this program, emphasis was placed on the role and expertise of a nurse in a community setting with vulnerable groups. In addition, exposure to distinct cultural groups and working within disadvantaged communities enabled professional development and a sense of increased responsibility towards their community. The authors postulate that guiding third year students through this type of reflection was a noteworthy accomplishment.

Participants also identified development in areas of competency such as: An intensification in reflective thinking, cultural awareness, adaptability, teamwork, openness, and tolerance; all in keeping with the fundamental presuppo- 
sitions of the profession, and essential in nursing practice. These findings agree with the evaluation of programs with similar objectives, ${ }^{[1,4,8,10]}$ and suggest that nursing programs should reinforce these types of initiatives.

Student participation in a similar exchange program (twosided, with focus on research in a vulnerable group, cultural exposure, comparing disparities in health access) may allow participants to address and discuss relevant ethical issues in nursing practice. These issues related to health inequalities, and potential research or nursing interventions amongst disadvantaged populations could be discussed and critiqued to foster ethical competencies in students.

In addition to the generic gains noted previously, this twosided exchange may provide an additional benefit related to learning dynamics through student interactions from different cultures and nursing education models. In line with Tjoflat et al., ${ }^{[8]}$ this first-hand experience of peer learning and development of communication skills in multilingual and multicultural teams appear more prominent when compared to unidirectional programs.

One additional finding was related to the 'gains' of this experience as exceeding explicit learning objectives identified at the beginning of the semester. Ortega et al. ${ }^{[15]}$ identified that programs that include global immersion could be considered transformational. The assessment of student participation in this exchange seems to support this position regarding transformation in both a personal and professional light.

\subsection{Recommendations for nursing education and future research}

The results of this study allowed a set of recommendations for nursing programs that aim to develop a two-sided global immersion experience to be comprised.

The reasons that students enroll in programs of this nature are very diverse. Regardless of their motivations, a broad range of competences were described with both personal and professional impact. Because of this, a comprehensive process of selecting students is suggested to allow the integration of academic, experiential, personal and professional expectations that include:

(1) Using creative methodologies, different from those offered conventionally, seem to act as a stimulus to student participation and unanticipated gains;

(2) Planning interventions based on group work methodologies support the development of team-related skills, and group support during new and stressful situations;

(3) Selecting a team that includes students in good standing, with positive faculty recommendations, the characteristics of flexibility, maturity, commitment, self- direction, critical thinking, and clinical judgment; with a face to face interview with faculty;

(4) Assigning student pairs (one from each country), before the exchange begins, may allow for improved communication, stronger work teams, and the potential for realizing more professional and personal "gains";

(5) Promoting interventions with vulnerable groups can add value to students' learning (awareness of professional responsibility towards the community and stimulating ethical reflection);

(6) Giving special attention to ongoing communication with students to allow for clear guidelines about the length and duration of their commitment to the exchange program; and,

(7) Conducting research that evaluates the short and longterm impact and effectiveness of two-sided exchange programs is needed.

\subsection{Limitations}

Study limitations included having a small sample $(\mathrm{N}=16)$ of third year nursing students from a relatively homogeneous age group. Due to small sample size and study design, it would be difficult to establish external validity, however, sufficient data may allow the reader to evaluate the transferability to other contexts. OSFG have many advantages for an international exchange program, with students from each focus groups providing rich responses. Some constraints to using OSFG may include not knowing when student responses to questions were completed before initiating the next question, and need for ongoing translation during OSFG with the Portuguese group. In addition, student perspectives may have been impacted as each group was exposed to a unique educational approach during preparation and post-exchange, related to course design, different academic calendars, and time allotted for didactic and clinical instruction.

\section{Conclusion}

Results strongly support that nursing students participating in international exchange programs develop important nursing competencies that can impact future practice, as well as students who are committed, tolerant, resourceful, and capable of critically appreciating the reality in which they live and work. This program broadened student horizons regarding the expanded role and practice of nurses. Special attention should be given to: (i) the selection of activities during an exchange to prompt student learning; (ii) the provision of adequate points in time to allow reflection of personal and professional experiences (positive and negative) during and following the exchange; and, (iii) a summary of length of student engagement, with concrete examples of the positive impact of their work, to provide closure post-exchange. 
In conclusion, universities should develop and foster programs for nursing students to engage in global learning opportunities.

\section{SUPPORT}

The DeMello Charitable Foundation.

\section{ACKNOWLEDGeMENTS}

Jessica de Lima, University of Pernanbuco-UPE.

\section{Conflicts of InTERest Disclosure}

The authors declare that there is no conflict of interest.

\section{REFERENCES}

[1] Bohman D, Borglin G. Student exchange for nursing students: does it raise cultural awareness? A descriptive, qualitative study. Nurse Education in Practice. 2014; 14(3): 259-264. https ://doi.org/ $10.1016 / j$. nepr.2013.11.006

[2] Repo H, Vahlberg T, Salminen L, et al. The Cultural Competence of Graduating Nursing Students. Journal of Transcultural Nursing 2017; 28(1): 98-107. https://doi.org/10.1177/1043659616 632046

[3] Button L, Green B, Tengnah C, et al. The impact of international placements on nurses' personal and professional lives: Literature review. Journal of Advanced Nursing. 2004; 50(3): 315-324 PMid:15811111 https://doi.org/10.1111/j.1365-2648. 20 $05.03395 . x$

[4] Curtin A, Martins DC, Schwartz-Barcott D, et al. Development and evaluation of an international service learning program for nursing students. Public Health Nursing. 2013; 30(6): 548-556. https://doi.org/10.1111/phn.12040

[5] Kohlbry P. The Impact of International Service-Learning on Nursing Students' Cultural Competency. Journal of Nursing Scholarship 2016; 48(3): 303-311. https://doi .org/10.1111/jnu. 12209

[6] Brach C, Fraser I. Reducing disparities through culturally competent health care: an analysis of the business case. Quality Management in Healthcare. 2002; 10(4): 15-28. PMid:12938253 https : //doi.org/10.1097/00019514-200210040-00005

[7] Kokko R. Future nurses' cultural competencies: what are their learning experiences during exchange and studies abroad? A systematic literature review. Journal of Nursing Management. 2011; 9(5): $673-$ 82. https://doi.org/10.1111/j.1365-2834.2011.01221.x

[8] Tjoflat I, Razaonandrianina J, Karlsen B, et al. Complementary knowledge sharing: Experiences of nursing students participating in an educational exchange program between Madagascar and Norway. Nurse Education Today. 2017; 49: 33-38. https ://doi .org/10.1 $016 / j . n e d t .2016 .11 .011$

[9] Greatrix-White S. Uncovering study abroad: Foreignness and its relevance to nurse education and cultural competence. Nurse Education Today. 2008; 28(5): 530-538.

[10] Kelleher S. Perceived Benefits of Study Abroad Programs for Nursing Students: An Integrative Review. Journal of Nursing Education. 2013; 52(12): 690-695. https://doi.org/10.3928/01484834 $-20131118-01$

[11] Tabi MM, Mukherjee S. Nursing in a global community: a study abroad program. Journal of Transcultural Nursing. 2003; 14(2): 134138. https://doi.org/10.1177/1043659602250637
[12] Green BF, Johansson I, Rosser M, et al. Study abroad: A multiple case study of nursing students' international experience. Nurse Education Today. 2008; 28(8): 981-992.

[13] Guskuma E, Dullius A, Godinho M, et al. International academic mobility in nursing education: an experience report. Revista Brasileira de Enfermagem. 2016; 69(5): 929-933. https://doi.org/10.1 590/0034-7167-2015-0128

[14] Haloburdo E, Thompson M. A comparison of international learning experiences for baccalaureate nursing students: Developed and developing countries. Journal of Nursing Education. 1998; 37: 13-21. PMid:9476730

[15] Ortega J, Mitchell E, Peragallo N. Beyond Borders: Global Nursing Education for the Future. Nursing Education Perspectives. 2016; $37(4)$.

[16] Tuckett A, Crompton P. Qualitative understanding of an international learning experience: what Australian undergraduate nurses and midwives said about a Cambodia placement? International Journal of Nursing Practice. 2014; 20(2): 135-141. https ://doi .org/10.1 $111 / i j n .12142$

[17] Polit DF, Beck CT. Nursing research: Generating and assessing evidence for nursing practice (9th ed.). Philadelphia, PA: Lippincott Williams and Wilkins; 2011. 482 p.

[18] Shinnamon AF, Gelmon SB, Holland BA. Methods and strategies for assessing service-learning in the health professions. San Francisco: Community Campus Partnerships for Health. 1999.

[19] Woodyatt CR, Finneran CA, Stephenson R. In-person versus online focus group discussions. Qualitative Health Research. 2016; 26(6): 741-749. https ://doi .org/10.1177/1049732316631510

[20] Stover CM. The use of online synchronous focus groups in a sample of lesbian, gay, and bisexual college students. Computers, Informatics, Nursing: CIN. 2012; 30(8): 395. https://doi .org/10.109 $7 /$ NXN . Ob013e3182636921

[21] Brosky JA, Deprey SM, Hoop JF, et al. Physical therapist student and community partner perspectives and attitudes regarding servicelearning experiences. Physical Therapy Education. 2006; 20(3): 4148.

[22] Sternas KA, O'Hare P, Lehman K, et al. Nursing and medical student teaming for service learning in partnership with the community: an emerging holistic model for interdisciplinary education and practice. Holistic Nursing Practice. 1998; 13(2): 66-77. https ://doi .org/10.1097/00004650-199901000-00011 